\title{
Influence of remaining coronal structure and finish line on the fracture strength of roots restored with metallic posts
}

\author{
Bruno Carlini-Jr ${ }^{(a)}$ \\ Doglas Cecchin ${ }^{(b)}$ \\ Gisele Damiana da Silveira \\ Pereira(c) $^{(c)}$ \\ Luis Alexandre Maffei Sartini \\ Paulillo(b)
}

(a) Department of Restorative Dentistry, Passo Fundo Dental School, University of Passo Fundo, Passo Fundo, RS, Brazil.

(b) Department of Restorative Dentistry, Piracicaba Dental School, State University of Campinas, Piracicaba, SP, Brazil.

(c) Department of Restorative Dentistry, Rio de Janeiro Dental School, Federal University of Rio de Janeiro, Rio de Janeiro, Rio de Janeiro, RJ, Brazil.

\begin{abstract}
The purpose of this study was to evaluate the fracture strength of roots that were prosthetically restored with metallic posts with or without any remaining coronal structure and with different finish lines. Sixty bovine incisors were sectioned below the cementoenamel junction, endodontically treated, and randomly divided into six experimental groups $(n=10)$ containing teeth with or without any remaining coronal structure, and with a beveled shoulder, a bevel, or a shoulder finish line design. The metallic posts were luted with dual-cured resin cement. The cores were made with composite resin, and metal crowns were cemented with zinc phosphate cement. The specimens were subjected to a tangential compressive load $\left(135^{\circ}\right.$ angle) at a crosshead speed of $0.5 \mathrm{~mm} / \mathrm{min}$ until failure, using a universal testing machine. The fracture strength data were analyzed using the ANOVA and LSMeans (least square means) tests $(\alpha=0.05)$. The data indicated that the teeth with $2 \mathrm{~mm}$ of remaining coronal structure showed the highest fracture strength values when compared with the teeth without any remaining structure $(\mathrm{p}<0.05)$. As to the different finish line designs, the highest fracture strength values were obtained for the beveled shoulder, followed by the bevel and then by the shoulder designs $(\mathrm{p}<0.05)$. It may be concluded that, to increase fracture strength, a beveled shoulder and $2 \mathrm{~mm}$ of remaining coronal structure are the ideal conditions.
\end{abstract}

Descriptors: Dental Cavity Preparation; Dental Restoration Failure; Tooth Root; Post and Core Technique; Compressive Strength.

\section{Introduction}

Endodontically treated teeth frequently require indirect restorations because of extensive loss of healthy tooth structure as a result of carious lesion or fracture. ${ }^{1}$ In these cases, the use of posts is recommended to promote retention of the final restoration. ${ }^{2-3}$

The preservation of tooth structure is an important factor in the successful restoration of endodontically treated teeth. Some authors ${ }^{4,5}$ have suggested that a tooth should have a minimum amount $(2 \mathrm{~mm})$ of coronal structure above the cementoenamel junction (CEJ) to ensure a proper shape of strength for a tooth. This coronal structure will provide a ferrule effect with the artificial crown that should prevent root fracture,
Received for publication on Jan 12, 2011 Accepted for publication on Apr 25, 2011 
post fracture and dislodgement.

The strength of a prosthetic restoration depends not only on the post and remaining coronal structure, but also on a suitable preparation and finish line design. ${ }^{4}$ In studies designed to investigate the fracture strength of metal and glass ceramic crowns, it was observed that tooth preparation with a $1.2-\mathrm{mm}$ shoulder finish line and a sharp axiogingival line angle produced the strongest crowns, whereas crowns fabricated for preparations with a chamfer finish line produced the weakest restoration. ${ }^{6,7}$ In contrast, some authors reported that the fracture strength of crowns luted with a resin luting agent was unaffected by the type of finish line used..$^{8,9}$ Rosen ${ }^{10}$ and Rosner ${ }^{11}$ reported that the beveled preparation design promoted a reduction in casting errors, a seal against tooth fracture, appropriate adaptation of the prosthesis and the establishment of the ferrule effect.

Thus, the purpose of this study was to evaluate the fracture strength of anterior tooth roots that were prosthetically restored with metallic posts with or without $2 \mathrm{~mm}$ of remaining coronal structure, and with a beveled shoulder, a bevel or a shoulder finish line design. The hypothesis tested was that the fracture strength of roots might be affected by the remaining coronal structure and by the finish line design.

\section{Methodology}

Sixty recently extracted bovine lower central incisors stored in $0.9 \%$ thymol solution at $4{ }^{\circ} \mathrm{C}$ were selected for use in this study. The teeth were transversally sectioned at their cervical portion, using a diamond double-faced disk (Extec, São Paulo, Brazil) mounted on a low-speed handpiece, and cooled with air/water spray. Thirty roots were standardized at a length of $17 \mathrm{~mm}$, whereas the other thirty were standardized at $19 \mathrm{~mm}$. This difference was used to generate the $2-\mathrm{mm}$ remaining coronal structure in half of the specimens.

The roots were embedded in polystyrene resin (Cromex, Piracicaba, Brazil) using a circular metal matrix $(25 \mathrm{~mm}$ in diameter by $20 \mathrm{~mm}$ in height). Adhesive material and elastic-based urethane (Nexus, Nucleus Duplex, Sweden) were used to simulate the periodontal ligament. All roots were embedded to a depth of $15 \mathrm{~mm}$, to maintain $2 \mathrm{~mm}$ of root length extending beyond the top of the acrylic resin in thirty roots, and $4 \mathrm{~mm}$ in the other thirty roots.

The root canals were prepared $1 \mathrm{~mm}$ short of the apex and filled with gutta-percha points (Dentsply Maillefer, Ballaigues, Switzerland) and Endomethasone root canal sealer (Septodont, Saint-Maur-DêsFossés, France). After root canal filling, the guttapercha points were all cut with size 3 Gates-Glidden burs (Dentsply Maillefer, Ballaigues, Switzerland), with a low-speed handpiece, maintaining $5 \mathrm{~mm}$ of filling material in the apical third of all specimens.

The roots without any remaining coronal structure and with $2 \mathrm{~mm}$ of remaining coronal structure were randomly divided into 6 groups $(n=10)$ according to different finish line designs: beveled shoulder, bevel or shoulder (Figure 1). The groups are described in Table 1.

The post spaces were prepared to a depth of $12 \mathrm{~mm}$ in the roots without any remaining coronal structure and to a depth of $14 \mathrm{~mm}$ in the roots with $2 \mathrm{~mm}$ of remaining coronal structure, using a drill supplied by the post manufacturer, mounted on a low-speed handpiece. Air/water spray cooling was used during preparation, and dentin thickness was standardized.

The root dentin was etched with 37\% phosphoric acid (FGM, Joinville, Brazil). Scotchbond MP Plus adhesive system (3M ESPE, St. Paul, USA) was then applied according to the manufacturer's recommendations and light-polymerized for $40 \mathrm{~s}$ with a curing unit (3M, Sumaré, Brazil) using a light intensity of $500 \mathrm{~mW} / \mathrm{cm}^{2}$. Metallic posts (Flexi-post, EDS of Brazil, São Paulo, Brazil) were cemented with dual-cured resin cement (Enforce, Dentsply Maille-

Table 1 - Groups, remaining coronal structure and finish line designs of the roots.

\begin{tabular}{c|c|c}
\hline Groups & Remaining Coronal Structure & Finish Line \\
\hline WOBS & Without & Beveled shoulder \\
\hline WOBE & Without & Bevel \\
\hline WOSH & Without & Shoulder \\
\hline WIBS & With & Beveled shoulder \\
\hline WIBE & With & Bevel \\
\hline WISH & With & Shoulder \\
\hline
\end{tabular}




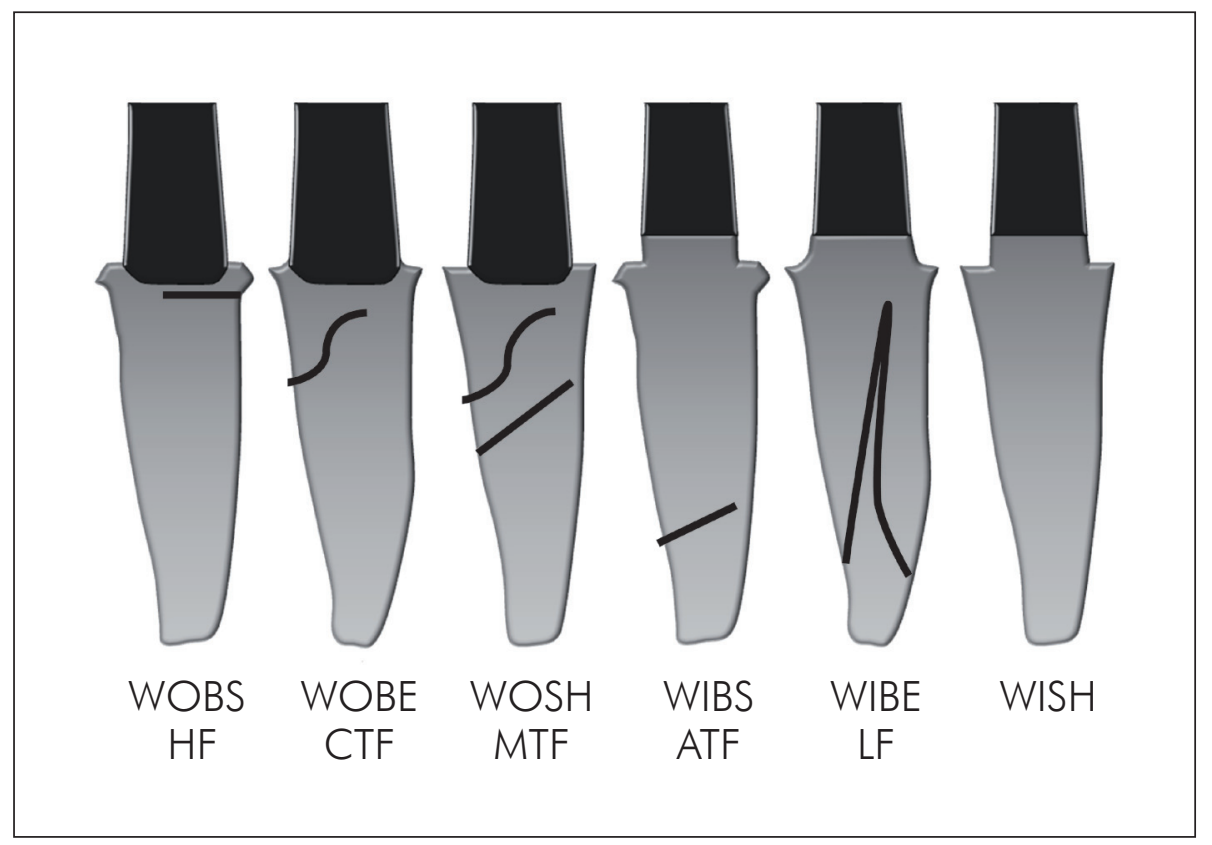

Figure 1 - Schematic illustration of the groups under study. WOBS, WOBE and WOSH stand for the groups without any remaining coronal structure, and, respectively, with a beveled shoulder, a bevel or a shoulder design. WIBS, WIBE and WISH stand for the groups with $2 \mathrm{~mm}$ of remaining coronal structure, and, respectively, with a beveled shoulder, a bevel or a shoulder design. The fracture locations observed for the experimental groups were as follows: HF, horizontal fracture; CTF, transverse fracture in the cervical third of the root canal; MTF, transverse fracture in the middle third of the root canal; ATF, transverse fracture in the apical third of the root canal; LF, longitudinal fracture of the root. fer, Ballaigues, Switzerland). The cement was mixed and introduced into the post spaces with a lentulospiral drill using a low-speed handpiece. ${ }^{12}$ Cement was also applied on the posts before they were gently seated by finger pressure and held in place for $60 \mathrm{~s}$. The cement was light polymerized for $30 \mathrm{~s}$ on each surface (buccal, palatal, mesial and distal), for a total 2-min light polymerization cycle.

The composite resin cores (Filtek Z250; 3M ESPE) were standardized with a 0.25 -mm-thick acetate matrix (Bio-art, São Carlos, Brazil) molded over the specimens in a vacuum-forming machine. The composite resin was placed in the acetate matrix in a single increment.

The finish line was prepared according to three different designs:

- beveled shoulder,

- bevel or

- shoulder.

The finish line was located at the limit between the tooth and the core for the teeth with no coronal remainder, and $2 \mathrm{~mm}$ below this limit for the specimens with remaining dental structure (Figure 1). The finish line axial depth was $1 \mathrm{~mm}$ in all groups. All specimens were finished with a no. 3216 diamond bur (KG Sorensen, Barueri, Brazil) at high speed and under water spray cooling.

The crown was replicated with silicone impression material (Aquasil Ultra, Dentsply Maillefer, Ballaigus, Switzerland) and poured in acrylic resin to make the other patterns. Rectangular-shaped stops with a central concavity were made on the palatine aspect of the patterns to locate and stabilize the metal tip during the fracture strength test. Standardized acrylic resin crowns were obtained for all teeth. All crowns were cemented with zinc phosphate cement (Zinc Cement, SS White, Rio de Janeiro, Brazil). The specimens were then stored in $100 \%$ relative humidity, at a constant temperature of $37( \pm 2){ }^{\circ} \mathrm{C}$ for a period of $48 \mathrm{~h}$ to ensure totally cured cement.

Next, the specimens were subjected to a compressive test in a universal testing machine (Emic DL 2000, Sao José dos Pinhais, Brazil). The position of the specimens was standardized using a device on the base of the apparatus, and load was applied at an angle of $135^{\circ}$ in relation to the long axis of the roots. ${ }^{13,14}$ An increasing oblique compressive load was applied on the cingulum of the tooth's palatal aspect ( $3 \mathrm{~mm}$ from the incisor edge), using a cylindrical-shaped device with a round tip $(2.7 \mathrm{~mm}$ in diameter). A cross-head speed of $0.5 \mathrm{~mm} / \mathrm{min}$ was applied until fracture. The root-post fragments set was removed from the acrylic resin after fracture and 
Table 2 - Compressive strength values observed in the experimental groups.

\begin{tabular}{c|c|c|c}
\hline Group & Minimum & Maximum & Mean \pm s.d. \\
\hline WOBS & 55.6 & 154.6 & $118.3 \pm 31.4^{\mathrm{c}}$ \\
\hline WOBE & 49.5 & 154.9 & $98.6 \pm 42.4^{\mathrm{d}}$ \\
\hline WOSH & 42.3 & 72.7 & $62.0 \pm 10.8^{\mathrm{e}}$ \\
\hline WIBS & 87.5 & 166.4 & $135.8 \pm 25.0^{\mathrm{a}}$ \\
\hline WIBE & 80.0 & 174.4 & $124.9 \pm 32.8^{\mathrm{a}, \mathrm{b}}$ \\
\hline WISH & 94.0 & 155.0 & $123.2 \pm 19.0^{\mathrm{b}, \mathrm{c}}$ \\
\hline
\end{tabular}

observed under a stereoscopic magnifying glass at $4 \times$ magnification for fracture analysis. The fractures were classified according to location as follows:

- horizontal fracture (HF) at the cementation line;

- transverse fracture in the cervical third of the root canal (CTF);

- transverse fracture in the middle third of the root canal (MTF);

- transverse fracture in the apical third of the root canal (ATF);

- longitudinal fracture of the root (LF) (Figure 1).

The data were analyzed by ANOVA and by LSMeans. The significance level was set at $5 \%$.

\section{Results}

The compressive loads required to fracture the roots in each of the 6 groups are displayed in Table 2.

The groups with $2 \mathrm{~mm}$ of remaining coronal structure (WIBS, WIBE and WISH) showed higher fracture strength values than those without any remaining coronal structure (WOBS, WOBE and WOSH) $(\mathrm{p}<0.05)$, except for Groups WOBS and WISH, which did not differ statistically $(\mathrm{p}<0.05)$. Regarding the preparation design, the highest fracture strength values were found for the beveled shoulder with or without any remaining structure $(\mathrm{p}<0.05)$. However, the beveled shoulder and the bevel designs did not differ statistically $(\mathrm{p}>0.05)$. Similar results were also observed when the bevel and the shoulder designs were compared within the groups with $2 \mathrm{~mm}$ of remaining coronal structure. The beveled shoulder design showed a fracture behavior similar to that of the bevel and the shoulder
Table 3 - Types of failure (number and percentage of teeth) for the experimental groups.

\begin{tabular}{c|c|c|c|c|c}
\hline Groups & HF & CTF & MTF & ATF & LF \\
\hline WOBS & $2(20 \%)$ & $2(20 \%)$ & $2(20 \%)$ & $2(20 \%)$ & $2(20 \%)$ \\
\hline WOBE & $2(20 \%)$ & $3(30 \%)$ & $3(30 \%)$ & $1(10 \%)$ & $1(10 \%)$ \\
\hline WOSH & $1(10 \%)$ & $1(10 \%)$ & $3(30 \%)$ & $1(10 \%)$ & $4(40 \%)$ \\
\hline WIBS & - & $2(20 \%)$ & $7(70 \%)$ & $1(10 \%)$ & - \\
\hline WIBE & $2(20 \%)$ & $2(20 \%)$ & $3(30 \%)$ & $1(10 \%)$ & $2(20 \%)$ \\
\hline WISH & - & $1(10 \%)$ & $5(50 \%)$ & $1(10 \%)$ & $3(30 \%)$ \\
\hline
\end{tabular}

designs $(p>0.05)$. The preparation designs affected the fracture strength values in the groups without any remaining structure, considering that a statistically significant difference was found $(\mathrm{p}<0.05)$.

Groups without any remaining coronal structure (WOBS, WOBE and WOSH) typically showed an LF, whereas most fractures in the other groups were MTF and CTF (Table 3).

\section{Discussion}

This study evaluated whether the remaining coronal dentinal structure and finish line design could interfere with the fracture behavior of an endodontically restored tooth. In general, the groups with remaining dental structure required higher values of compressive load to promote root fracture. These results are in agreement with those of the studies by Varvara et al..$^{15}$ and $\mathrm{Ma}$ et al. ${ }^{16}$ After prosthetic preparation, the remaining coronal structure becomes part of the axial wall of the core, and subsequent cementation of the crown will lead to a ferrule effect that increases the fracture resistance of the root. The increase in resistance is explained by the greater preservation of dental structure and by a reduction of the lever effect of the post on the root canal walls. ${ }^{4}$

For the groups without any remaining dental structure, the beveled shoulder design presented the highest fracture resistance values, which were similar to those obtained by the group with remaining structure and a shoulder design. This could be explained by the fact that the bevel extended $1 \mathrm{~mm}$ beyond the limit between the root and the prosthetic core, and, when embraced by a metal band, this type of finish line is capable of increasing the fracture resistance of the root/core/prosthetic crown set. ${ }^{4}$ Hence, these 
results demonstrated that, even in the presence of remaining coronal dentin, the type of finish line design still influences fracture resistance values.

The lowest fracture strength values were found for the shoulder design without any remaining structure, a preparation configuration which lacks a wall in dentin for the prosthetic crown to embrace. As a result, all the oblique force exerted on the crown is supported directly by the prosthetic core and transmitted successively to the post and root canal, generating a lever effect on the root wall. The bevel design was extended beyond the limit between the root and the prosthetic crown, involving about $0.5 \mathrm{~mm}$ of root dentinal structure. This feature allowed embracing only a small quantity of dental structure by the prosthetic crown, providing less ferrule effect than that achieved with the beveled shoulder, and leading to lower resistance values.

In the groups with remaining coronal dental structure, the beveled shoulder and the bevel designs showed similar behavior, a fact which could be attributed to the prosthetic crown having involved part of the root dentinal structure. The groups without any remaining coronal structure and with a beveled shoulder design behaved similarly to the group with remaining coronal dental structure and a shoulder design, which allows us to conclude that the ferrule effect is achieved in a similar manner by using the cervical bevel or involving the coronal structure on the axial wall of the core. Moreover, there is an indication of synergism, considering that the highest fracture resistance values were achieved when there was remaining coronal structure at the gingival bevel. This combination of a remaining dental structure and the construction of a metal band can be used in cases of teeth with a short clinical crown, in which esthetics is not a preponderant factor and when the oblique forces on the prosthetic crown exceed the normal mastication forces, as is the case of teeth with fixed partial or removable dentures, adjacent to distal extensions or large prosthetic spaces.

Analysis of the fracture pattern demonstrated a greater trend towards longitudinal fractures (LF) for the groups without any remaining coronal structure, whereas there was predominance of fractures in the middle and cervical thirds of the root for the groups with remaining coronal structure, evidencing the protection exerted by the ferrule effect against longitudinal fractures. ${ }^{16,17}$ Similarly, there was a trend towards longitudinal fractures for the shoulder design, contrasting with the beveled shoulder and bevel designs, which presented a trend towards transverse fractures in the middle third. The results of this analysis highlight the importance of preserving the coronal dental structure and involving it in the preparation, as well as that of the ferrule effect achieved by constructing a metal band. The beveled design showed a behavior similar to that of the beveled shoulder design with regard to the predominant fracture pattern. The fracture pattern has great clinical relevance, since it dictates the possibility of reconstructing the remaining dental structure. In this study, preservation of healthy tooth structure and its later involvement in the prosthetic preparation contributed to the occurrence of less catastrophic fractures, in comparison with those observed in teeth without any remaining coronal structure, or without a bevel to be embraced by the metal belt provided by the metal prosthetic crown. The strength of the prosthetic restoration appears to be primarily related to the quantity of remaining coronal structure involved in the preparation, ${ }^{16}$ and secondly to the finish line design.

In case of teeth without any remaining dental structure, the possibility of augmenting the clinical crown should be evaluated, or of performing root traction, in order to involve healthy dental structure in the prosthetic preparation..$^{12}$ In the event that these procedures are not possible, it is suggested that a beveled finish line be chosen so that a metal belt can embrace the root. The adhesive technique with resin composite and pre-fabricated fiber posts is recommended because it forms a single block between the root and the filling core. Nevertheless, further studies should be conducted to confirm these recommendations.

\section{Conclusion}

Based on the results of the present study, a beveled shoulder design should be adopted with a $2-\mathrm{mm}$ minimum remaining coronal structure to achieve higher values of resistance to fracture. 


\section{References}

1. Bitter K, Kielbassa AM. Post-endodontic restorations with adhesively luted fiber-reinforced composite post systems: a review. Am J Dent. 2007 Dec;20(6):353-60.

2. Ottl P, Hahn L, Lauer H, Fay M. Fracture characteristics of carbon fibre, ceramic and non-palladium endodontic post systems at monotonously increasing loads. J Oral Rehabil. $2002 \mathrm{Feb} ; 29(2): 175-83$.

3. Spazzin AO, Galafassi D, de Meira-Júnior AD, Braz R, Garbin CA. Influence of post and resin cement on stress distribution of maxillary central incisors restored with direct resin composite. Oper Dent. 2009 Mar-Apr;34(2):223-9.

4. Sorensen JA, Engelman MJ. Ferrule design and fracture resistance of endodontically-treated teeth. J Prosthet Dent. 1990 May;63(5):529-36.

5. Wagnild GW, Mueller KL. Restoration of the endodontically treated tooth. In: Cohen S, Burns RC, editors. Pathways of the pulp. 8th ed. St. Louis: Elsevier; 2001. p. 765-95.

6. Doyle MG, Munoz CA, Goodacre CJ, Friedlander LD, Moore BK. The effect of tooth preparation design on the breaking strength of Dicor crowns: II. Int J Prosthodont 1990 MayJun;3(3):241-8.

7. Doyle MG, Goodacre CJ, Munoz CA, Andres CJ. The effect of tooth preparation design on the breaking strength of Dicor crowns: III. Int J Prosthodont 1990 Jul-Aug;3(4):327-40.

8. Bernal G, Jones RM, Brown DT, Munoz CA, Goodacre CJ. The effect of finish line form and luting agent on the breaking strength of Dicor crowns. Int J Prosthodont 1993 MayJun;6(3):286-90.

9. Malament KA, Socransky SS. Survival of Dicor glass-ceramic dental restorations over 16 years. Part III: effect of luting agent and tooth or tooth substitue core structure. J Prosthet Dent 2001 Nov;86(5):511-9

10. Rosen H. Operative procedures on mutilated endodontically treated teeth. J Prosthet Dent 1961 Sep-Oct;11:973-86.

11. Rosner D. Function, placement, and reproduction of bevels for gold casting. J Prosthet Dent 1963;13:1160-66.

12. Fonseca TS, Alfredo E, Vansan LP, Sila RG, Sousa YT, Saquy $\mathrm{PC}$, et al. Retention of radicular posts varying the application technique of the adhesive system and luting agent. Braz Oral Res. 2006 Oct; 20(4):347-52.

13. Lima AF, Spazzin AO, Galafassi D, Correr-Sobrinho L, Carlini-Júnior B. Influence of ferrule preparation with or without glass fiber post on fracture resistance of endodontically treated teeth. J Appl Oral Sci 2010 Jul-Aug;18(4):360-3.

14. Cecchin D, Farina AP, Guerreiro CAM, Carlini-Júnior B. Fracture resistance of roots prosthetically restored with intra-radicular posts of different lengths. J Oral Rehabil. 2010 Fev;37(2):116-22.

15. Varvara G, Perinetti G, Di Iorio D, Murmura G, Caputi S. In vitro evaluation of fracture resistance and failure mode of internally restored endodontically treated maxillary incisors with differing heights of residual dentin. J Prosthet Dent. 2007 Nov;98(5):365-72.

16. Ma PS, Nicholls JI, Junge T, Phillips KM. Load fatigue of teeth with different ferrule lengths, restored with fiber posts, composite resin cores, and all-ceramic crowns. J Prosthet Dent. 2009 Oct;102(4):229-34.

17. Morgano SM, Bracket SE. Foundations in fixed prosthodontics: Current knowleddge and future needs. J Prosthet Dent. 1999 Dec;82(6):634-57. 